\section{International Scientific Journal Theoretical \& Applied Science}

p-ISSN: 2308-4944 (print) e-ISSN: 2409-0085 (online)

Year: 2017 Issue: $01 \quad$ Volume: 45

Published: $30.01 .2017 \quad$ http://T-Science.org
Sanjarbek Abdurazakovich Djumanov

Senior scientific researcher of the chair of

"History of Uzbekistan" of

Samarkand State University

Samarkand, Uzbekistan

kamola_nuz@rambler.ru

SECTION 13. Geography. History. Oceanology. Meteorology.

\title{
ACCORDING TO THE MEASURES TO ENSURE UZBEKISTAN'S HEALTH CARE SYSTEM WITH MEDICAL EQUIPMENT (1991-1996 YEARS)
}

Abstract: During the years of independence, a number of events on providing medical institutions with medical techniques were held in Uzbekistan. Especially those activities which held in the early years of independence were of great importance.This article from a scientific point of view highlights the history of those events during 1991-1996 years.

Key words: Union of "Uztibtekhnika”, medical equipment, reforms agro-industrial union, Service of visual optics, foreign partnership, "Mediz" plant, state credit.

Language: English

Citation: Djumanov SA (2017) ACCORDING TO THE MEASURES TO ENSURE UZBEKISTAN'S HEALTH CARE SYSTEM WITH MEDICAL EQUIPMENT, 1991-1996 YEARS. ISJ Theoretical \& Applied Science, 01 (45): 48-51.

Soi: http://s-o-i.org/1.1/TAS-01-45-7 Doi: crossef https://dx.doi.org/10.15863/TAS.2017.01.45.7

\section{Introduction}

It is known that the population of Uzbekistan dramatically suffered under harsh reign of the USSR. The developmental lag in terms of technics and technology which was considered one of the most adversely affecting features of that time, swept among the Uzbek people as did it into the rest countries of former Soviet Union. Particularly, that circumstance was obviously noticed in the field of health care system. The degree of providing medical equipment valuable for maintaining population's health wasamong the least plans and not appropriately paid attention in former Soviet Union. Taking into consideration the fact of being behind concerning technics and technologies of the USSR from developed countries of the world, the situation in Uzbekistan would become more evident. For instance, according to the information of 19891990's, even though there was an institution called "Uztibtekhnika" (Uzbekistan Medical Technics) its activity was poorly developed. Especially, during the end of 1989 and at the beginning of 1990, the pace of inadequate providing of medical technics considerable went up, the condition became worse and the usage of those technologies was not properly carried on[1:173]. Later all those amiss deeds displeased Uzbek population. Furthermore, this worsened the situation in Uzbekistan where natural growth of population is high. For paradigm, the natural growth of Uzbek population composed 593 thousand and 126 people according to the data of 1990[2].

\section{Materials and Methods}

Moreover, there were significant discrepancies between separated budget fund for medical equipment and purchase orders done for them. As an example, because of differences between separated budget money for medical equipment and purchase orders a great number of odd products left unsold in the stores of manufactory "Uztibtekhnika". Particularly, on July 1 in 1991aggragate value of excess goods in the stores of "Uztibtekhnika" totaled over 18.1 million sums[3:20]. It was unique politics of that time just "showing abundance" instead of using resources appropriately. In addition, deficiency, embezzlement and burden of people emphatically deepened. For example, in accordance with the information obtained in the first half of 1991, deficiency, waste and stealing making up 7116 sums were revealed[3:20]. Those conditions could be considered as the results of widely-spread notorious habit of former Soviet Union.

In addition, although a network of many factories specialized on mending medical equipment existed, a lot of parts of medical tools were not 
repaired properly. For example, only those medical devices and apparatus composing 161.1 million sums were repaired, indeed, the government must have spent 201.3 million that the total amount of money of all equipment which health care institutions of Uzbekistan had[1:173]. Enterprises of "Tibtekhnika" did not often repair radiological technics, shortwave diagnostic tools, endoscopic devices and cryogen medical equipment. All that happened was because of the poor quality of material-technic foundation of amendatory enterprises of "Tibtekhnika". As 5 manufactories out of 13 possessed with appropriate bases[1:174].

For those reasons, from the first days after reaching independence, Uzbekistan commenced to pay much attention to the development of all spheres and especially, the realm of health care system and did all efforts to provide all medical institution with the latest medical technics. At the beginning it was a bit difficult to realize because of financial and economical hindrances. As a prove, the statistical data on 9 month-period of financial economic activity of Health Care Organizations of Uzbekistan given at the end of 1992 reported that enterprises under Republic Health Care institution "Tibtekhnika" were not able to do payment of mending equipment in time because of deficiency in budget[4:41]. Furthermore, the absence of plants specialized on producing medical equipment in the Republic worsened situation. Later "Uztibtekhnika" taking into the consideration almost every single detail, implemented a number of rules, orders and made alterations to create reservations of widely used products as well as improve the quality of medical serving institutions in the Republic. Particularly, contracts were signed with plants specialized on producing medical equipment and tools. A lot of organizational alterations were made in order to improve potentiality of Republic's industries specialized in producing medical devices and funds of local agro industrial institutions were involved to buy foreign medical technologies. Changes having been made in time allowed not to stop processes of treatment diagnostics and helped to provide prevention (prophylactic) organizations with necessary medical equipment within the early two years of independence[5:115].

Moreover, negotiations were conducted on creating medical equipment with number of medical institutions and factories of the Republic. Instrument of blood transfusion, catheters, urine collecting bags were about to be produced in the Republic, in addition, to improve amount of producing disposable (medical) syringes techno-financial plans of widening and reconstructing the plant of "MEDIZ" were discussed[5:116]. Taking into account the situation in the country, on issue of investing extra money, beside the budget, a lot of work was done among the directors and heads of the medical institutions of the Republic. Particularly, 322.5 million sums was separated according to 1992 year's Republic plan for medical spending, but actually health care institutions bought medical equipmentcomposing 521.5 million sums. Exactly, another extra 199 million sums was spent to buy medical tools[5:116]. In leaps and bounds, this significantly improved the process of providing medical institutions with medical tools.

However, all those were not always easily done because of some objective reasons. One of the most influential reasons was all habits and monopolistic features inherited by former Soviet Union of some chairmen of the medical health care institutions. For example, as it was said in the Meeting of members of Ministry of Health Care Institutions, the tools kept in the medical institutions were not carefully used and the condition of was not regulated by the heads of the health care institutions of the Republic. While investigating the health care organizations of Tashkent city, Tashkent and Bukhara regions it became apparent that medical tools were not utilized enough[5:10].

Despite some aforementioned unpleasant deeds further bright alterations were constantly made. This system was being developed to be stoical for market economy relations. Particularly, within 9 months of 1994 there were 197 documents applied to Republic and State Property institution from "Tibtekhnika" organizations to make medical institutionsprivate and after discussion 157 documents were approved and those started their activity as privatized estates[6:94]. At the end of the year a number of private companies increased to 200[8:160]. Among those 5 objects turned into a joint-stock company, 30 of them became public and 165 objects were made private ones[7:58]. All those alterations gave fruitful and exact results in economic activity for "Uztibtekhnika" manufacturing institutions' branches.For example, in 1994 turnover capital was not 16510.9 sums as it ought to have been, but much more 25717.0 sums or the plan was done for 155.7 $\%$. Furthermore, medical equipment totaling 22423.2 thousand sums was sold to health care institutions of the Republic. Population spent 3293.8 thousand sums to purchase medical products such as optical eyeglasses and other medical tools[5:160]. It led to entering into market economy and at the same time became an important factor to develop population's knowledge in terms of market economy and medical improvement.

Besides, partnership relations with foreign companies were also established. For instance, within 9 months of 1994, medical equipment aggregating 42.7 thousand sums was brought, and among those amount of tools brought from Russia composed 10.6 thousand sums and for tools from Ukraine the Republic spent 32.1 thousand sums[6:106]. 
Meetings were always held to prevent lacks in terms of medical services and existence of appropriate equipment. For example, for this purpose "Uztibtekhnika" Republic manufacturing institution conducted some activities to produce some medical technologies in the area of the Republic. As a result, the republic was able to set up producing more than 30 types of medical technic products, and their quantity made up 5.2 thousand sums in 1994[7:161].

In 1995 those processes were continued to be conducted widely. Changes that should have been made proved their outcome in one-year-report of work of "Uztibtekhnika". For instance, according to that the main purpose was to establish "Uztibtekhnika" Holding association. The new association was to maintain the processes of medical services and producing medical instruments. And the first step was to establish a plant which would produce surgery sewing material - surgical catgut. That company was planned to be finished in the second half of 1996. What's more, in 1995-1996 years in order to increase producing potentiality and reduce medical lack, the republic decided to widen the activity of the plant "Mediz" specialized in producing disposable syringes and aimed to aggrandize the number of syringes to 200 million[7:58].

Moreover, the politics of the Republic meant to develop relationships with foreign countries. For example, because of credit cooperation with exportcredit institution named "AKA", a lot of plans were realized to purchase medical equipment from Germany and it gave successful results immediately in 1995. As a result, a lot of rare technologies were imported into the Republic, in addition the country planned to buy medical equipment for 16 million dollars from KEC credit.

All realized work continued giving results even in 1996. For instance, within 9 months of that year through the network plants of "Tibtekhnika" medical technics composing 626.2 million sums were sold, exactly, $115 \%$ in percentage, indeed the amount should have been 544.5 million sums. Turnover of products rose 1,7 times as compared to nine months of 1995. Overall profit gained form selling medical equipment within nine months of 1996 made up 18,9 $\%$ as compared to turnover of goods, moreover selling medical equipment through centralized state fund totaled $11,5 \%[8: 173]$.

\section{Conclusion}

In conclusion, it can be said that within five early years of independence the processes of providing medical institution with appropriate medical equipment were quite complicated. One of the most influential factors was useless system inherited from former Soviet Union and difficulties of getting rid of that system as soon as possible. Thanks to all prosperous alterations of our government, we were able to renew the system and conditions of medical institutions created by Soviet Union and tried to provide with necessary qualitative medical technologies almost every medical institution within the years we analyzed above. Instead of former public medical institutions, the Republic let those institutions be privatized, also modern technologies were brought from foreign countries, built many manufacturing powers, trained qualified personnel for organizations, close relations with foreign countries' companies and firms were developed and all those helped Uzbekistan to become known in the world and create basis of modern circumstances. In this field alterations were made in accordance with our country's strategy without any revolutionary leap, and people periodically became accustomed to understanding the notions of market economy. That prosperous politics not only helped to get successful results, but also served as the greatest power to develop new ideological thoughts in mindsets of people.

\section{References:}

1. Central State Archives of the Republic of Uzbekistan On Scientific, Technical and Medical Documents Fund-M-372, the $1^{\text {st }}$ list, the $9^{\text {th }}$ folding volume

2. The report of State Statistics Committee of the Republic of Uzbekistan

3. Central State Archives of the Republic of Uzbekistan On Scientific, Technical and Medical Documents Fund-M-372, the $1^{\text {st }}$ list, the $11^{\text {th }}$ folding volume
4. Central State Archives of the Republic of Uzbekistan On Scientific, Technical and Medical Documents Fund-M-372, the $1^{\text {st }}$ list, the $88^{\text {th }}$ folding volume

5. Central State Archives of the Republic of Uzbekistan On Scientific, Technical and Medical Documents Fund-M-372, the $1^{\text {st }}$ list, the $165^{\text {th }}$ folding volume

6. Central State Archives of the Republic of Uzbekistan On Scientific, Technical and 


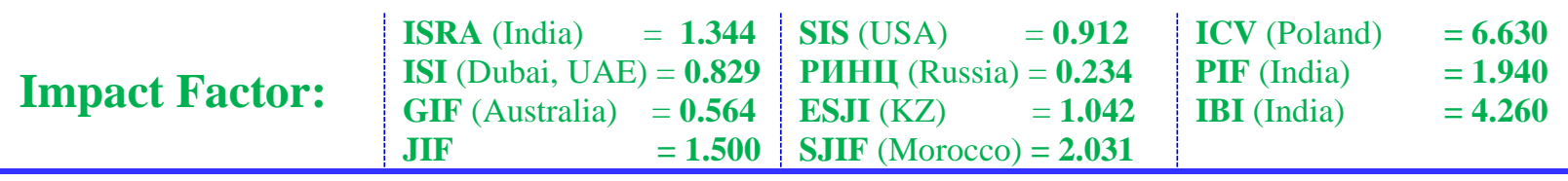

Medical Documents Fund-M-372, the $1^{\text {st }}$ list, the $240^{\text {th }}$ folding volume

7. Central State Archives of the Republic of Uzbekistan On Scientific, Technical and Medical Documents Fund-M-372, the $1^{\text {st }}$ list, the $314^{\text {th }}$ folding volume
8. Central State Archives of the Republic of Uzbekistan On Scientific, Technical and Medical Documents Fund-M-372, the $1^{\text {st }}$ list, the $374^{\text {th }}$ folding volume 